\title{
Local indigenous strategy to rehabilitate and conserve mangrove ecosystem in the southeastern Gulf of Kupang, East Nusa Tenggara, Indonesia
}

\author{
RONGGO SADONO ${ }^{1, \vartheta}$, DJOKO SOEPRIJADI ${ }^{1}$, ARI SUSANTI ${ }^{1}$, JERIELS MATATULA ${ }^{2, \bullet v}$, EKO PUJIONO ${ }^{3}$, \\ FAHMI IDRIS ${ }^{4}$, PANDU YUDHA ADI PUTRA WIRABUANA ${ }^{1,4}$ \\ ${ }^{1}$ Department of Forest Management, Faculty of Forestry, Universitas Gadjah Mada. Jl. Agro No. 1, Bulaksumur, Sleman 55281, Yogyakarta, Indonesia \\ Tel./fax.: +62-274-548815, vemail: rsadono@ugm.ac.id \\ ${ }^{2}$ Forestry Field Program, Politeknik Pertanian Negeri Kupang. Jl. Prof. Herman Johanes, Lasiana, Kupang 85011, East Nusa Tenggara, Indonesia. \\ Tel./fax.: +62-380-881600, ^vemail: jerielsforestry@ gmail.com \\ ${ }^{3}$ Forestry Research Agency of Kupang, Ministry of Environment and Forestry. Jl. Alfons Nisnoni No.7, Air Nona, Kupang 85011, East Nusa Tenggara, \\ Indonesia. \\ ${ }^{4}$ Department of Research and Development, TROFSIT. Jl. Kaliurang Km 16, Sleman 55281, Yogyakarta, Indonesia
}

Manuscript received: 14 November 2019. Revision accepted: 28 February 2020.

\begin{abstract}
Sadono R, Soeprijadi D, Susanti A, Matatula J, Pujiono E, Idris F, Wirabuana PYAP. 2020. Local indigenous strategy to rehabilitate and conserve mangrove ecosystem in the southeastern Gulf of Kupang, East Nusa Tenggara, Indonesia. Biodiversitas 21: 1250-1257. The existence of local communities around mangrove ecosystems plays essential role to support the effort of conservation programs in this area. This study is aimed to investigate a set of situation faced by local communities in the southeastern Gulf of Kupang (SGK), East Nusa Tenggara Province which led to the rehabilitation of once degraded mangrove forests in SGK and the strategies to conserve the recovered mangrove forests. A case study approach was developed using purposive sampling to collect information regarding the historical situation of mangrove forests in SGK. Further, remote sensing method using multi-temporal observation data was used to investigate the changes in mangrove cover from 1994 to 2019. This study revealed that a series of situations became the fundamental of the success in retaining the existence of mangrove ecosystems in SGK. First, the negative impacts of mangrove degradation affected the communities badly in relation to their livelihoods in fisheries and marine sector as well as other environmental services. Then, this situation led to the emergent of a local champion to initiate mangrove rehabilitation efforts which firstly did not get attention from most of the communities. After some initial successes, the efforts of the local champion was then followed by other members of communities, triggering a bigger scale of mangrove rehabilitation. Having the mangrove recovered, the communities set of highly strict local indigenous rules in which every indigenous people who conducting illegal logging in the mangroves would be expelled from the village, while a large fine was given for outside people who did the similar action. Currently, more than $90 \%$ of respondents have understood the benefits of mangroves and derived advantages from it, particularly in improving their prosperity and security. The results of the success of mangrove rehabilitation and conservation in SGK was confirmed by the increasing extent of mangrove vegetation using remote sensing data. The case study of rehabilitation and conservation in SGK provided valuable learning for communities in other areas.
\end{abstract}

Keywords: A set of highly strict rules, indigenous tribes, mangrove ecosystems, multi-temporal remote sensing, prosperity and security benefits

\section{INTRODUCTION}

The existence of mangrove ecosystems plays essential roles in providing environmental services in the coastal area such as preventing abrasion, averting sea-water intrusion, and serving as windbreak (Matatula et al. 2019). It is a habitat for a number of sea organisms like fish, shrimp, crab, plankton, and benthos (Sihombing et al 2017). The mangrove forest is also a source of high economic products, mainly from tannins and fisheries (Kusmana and Sukristijiono 2016). A study shows that the presence of mangroves has a positive contribution to climate change mitigation by sequestering and storing carbon (Taillardat et al. 2018). Hence, sustainable mangroves management become an emerging issue in many countries, including Indonesia.

Approximately 4.5 million hectares of mangrove ecosystems are distributed in Indonesia (Susilo et al. 2017).
It is equivalent to $23 \%$ of the total mangrove forests around the world (Richards and Friess 2016). Unfortunately, more than $50 \%$ of mangroves in Indonesia are degraded due to the impact of human activities like illegal logging, environmental pollution, reclamation, and land-use change (Ilman et al. 2016). Consequently, the quality of mangroves declines rapidly and can not supply optimum functions to support the life cycle process in the coastal area. It also causes negative impacts on the surrounding ecosystems like coral reef and seagrass (Guannel et al. 2016).

In order to recover the degraded and deforested mangroves, the implementation of reforestation programs is urgently required. As with other reforestation efforts, mangrove reforestation is almost impossible implemented without the participation of communities since they have an essential role as the main actor to conduct reforestation activities, starting from planning, implementing to longterm monitoring (Budiharta et al. 2016). In this case, the 
existence of community is not only as reforestation implementer, but also as the object who will receive the benefit of mangrove reforestation in the long-term period.

Several studies explain the participation of communities is one of the most important factors that affect the success of reforestation activities in the mangroves (Le et al. 2012; Wylie et al. 2016; Eddiwan 2018). The awareness of communities regarding the benefits of mangrove forests can accelerate the execution of programs. Moreover, they will also help to maintain the sustainability of the mangroves after reforestation. Over the last periods, there are many coastal areas that have initiated to rehabilitate the mangroves area. However, only a few areas are successful to achieve the objectives. One of them is a coastal area located in the southeastern Gulf of Kupang (SGK).

The sustainability of mangrove ecosystems in SGK is an excellent example of the effort of indigenous communities to restore mangroves. There are three local ethnics living in SGK, namely Rote, Sabu, and Timor. Before 1990s, this area was only inhabited by Rote ethnic, but after 1990s other ethnicities like Sabu and Timor have begun to live in SGK. All ethnicities have a similar characteristic in which they highly depend on agriculture and fisheries to support their life. Unfortunately, in 1993, the mangrove forests in SGK were degraded quickly as it was converted to sand mining area. Many negative impacts affected local indigenous communities from 1993 to 1994 due to sand mining, yet the mangrove destruction provided valuable learning for communities related to the benefits of mangrove forests in supporting their lives. In early1994, an initiative movement for mangroves rehabilitation was started in SGK. Until now, the effort has been successful in improving the mangroves vegetation cover. Despite the potentials that the story of mangrove rehabilitation in SGK could be learning materials for reforestation programs of mangroves in other areas, the complete information regarding this was not well documented. This study is aimed to investigate a set of situation faced by local communities leading to the rehabilitation of once degraded mangrove forests in SGK and the strategies to conserve the recovered mangrove forests.

\section{MATERIALS AND METHODS}

\section{Study period and area}

This study was conducted in mangrove ecosystems, located in the southeastern Gulf of Kupang (SGK) from October to November 2019. The area included three villages namely Oebelo, Tanah Merah, and Noelbaki of Kupang District (Figure 1). This site had dry conditions with annual rainfall ranging from $1,500 \mathrm{~mm}$ year- ${ }^{1}$. Topography was dominated by flat area with slope level varying $0-2 \%$.

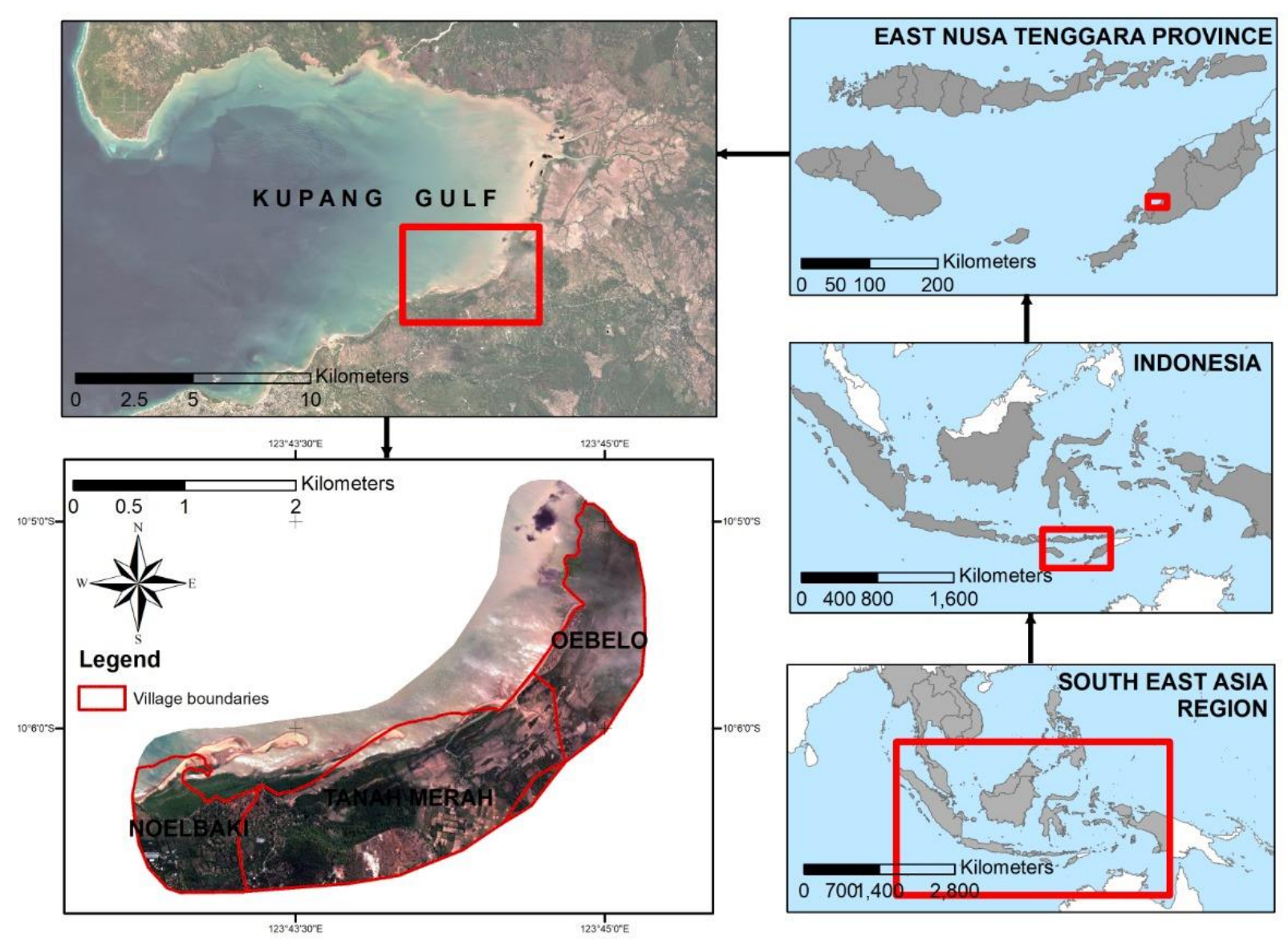

Figure 1. Location of mangrove ecosystems in the southeastern of Kupang Gulf, East Nusa Tenggara, Indonesia 


\section{Data collection procedures}

A case study approach was developed to investigate the history of mangroves rehabilitation in SGK. It was conducted by two stages, i.e. literature review and deep interview (Bengtsson 2016). The objective of literature reviews in this study was to collect any information related to the history of mangrove ecosystems management in the study area. It could be derived from government documents, academic publications, or other relevant articles about mangroves in SGK. While the deep interview was directed to confirm the number of information that was obtained from literature reviews. It also aimed to identify the motivation of indigenous communities in preserving mangroves and explore the local strategies for retaining it. The process of deep interview was done by purposive sampling with total respondents around 32 people consisting of indigenous leaders, village officials, farmers, fishermen, and teenagers. A set of questionnaires was also used to assess the knowledge of respondents about the importance of sustainable mangroves management. It was also utilized to clarify whether the indigenous communities received advantages directly from the existence of mangroves ecosystems.

Furthermore, a remote sensing method using multitemporal observation was used to cross-check the effectiveness of local indigenous strategies in mangroves rehabilitation and sustaining its ecosystems (Islam et al. 2018). A series of medium resolution image was selected to detect the change of mangroves cover in the study area using LANDSAT with spatial resolution around $30 \mathrm{~m}$. Those images were acquired from USGS in different periods (Table 1). The mangrove covers were identified from NDVI (Normalized Density Value Index). It was started by the correction process of radiometric and geometry on LANDSAT in every period. Then, NDVI was calculated by equation (Umroh et al. 2016) :

$$
\mathrm{NDVI}=(\mathrm{NIR}-\mathrm{RED}) /(\mathrm{NIR}+\mathrm{RED})
$$

Where NIR was the near-infrared band reflectance and RED described the red band reflectance from a sensor. A mangrove forest commonly had NDVI ranging from $0.4-$ 0.6 (Zhang et al. 2016).

\section{Data analysis}

Data were analyzed descriptively by historical explanation of the results from literature reviews and deep interviews. The comparison of mangrove covers in each period was demonstrated visually by maps obtained from remote sensing data.

\section{RESULTS AND DISCUSSION}

\section{Mangrove forest dynamics in SGK and its impacts on communities' life}

Total area of mangrove forest in SGK ranged \pm 600 ha, consisting of several species such as Rhizophora stylosa, Ceriops tagal, Avicennia lanata, A. alba, A. marina, and Sonneratia caseolaris. According to the information obtained from local indigenous leaders, mangroves degradation in this area began in 1993 due to the impacts of sand mining and illegal logging. The activity of sand mining was directly permitted by the local government to support urban development, while the illegal logging in mangrove forests was done by local communities to supply firewood for the bricks and salt manufacture industry. This circumstance had occurred in long periods and provided negative impacts on community's life around SGK. For example, before the mangroves degraded, local indigenous communities could simply catch fish, shrimps, and crabs in the mangroves area without sailing too far. However, after the degradation of mangrove ecosystems happened, they should sail away by approximately $50 \mathrm{~km}$ to get marine and fishery products. Moreover, the decrease of the mangrove forests also can no longer mitigate the high tide in the area of settlements, particularly at the full moon period.

The statement of local indigenous leader was confirmed by the results of remote sensing analysis that exhibited the different mangrove covers in SGK from 1990 to 2019 (Figure 2). Referring to the visual data derived from remote sensing, the percentage of mangrove cover obviously declined around 20\% from 1990 to 1994.

Table 1. List of medium resolution images for identification of mangrove covers in southeastern Gulf of Kupang (SGK) using NDVI

\begin{tabular}{llcc}
\hline \multicolumn{1}{c}{ Periods } & \multicolumn{1}{c}{ LANDSAT Images } & Band Formula NDVI & Spatial Resolution \\
\hline September 14, 1990 & LANDSAT 5 TM & 4 NIR \& 3 RED & $30 \mathrm{~m}$ \\
May 30, 1994 & LANDSAT 5 TM & 4 NIR \& 3 RED & $30 \mathrm{~m}$ \\
July 13, 1999 & LANDSAT 7 ETM+ & 4IR \& 3 RED & $30 \mathrm{~m}$ \\
July 10, 2004 & LANDSAT 7 ETM+ NIR \& 3 RED & $30 \mathrm{~m}$ \\
June 6, 2009 & LANDSAT 7 ETM+ & 4 NIR \& 3 RED & $30 \mathrm{~m}$ \\
July 30, 2014 & LANDSAT 8 OLI & 5 NIR \& 4 RED & $30 \mathrm{~m}$ \\
June 26, 2019 & LANDSAT 8 OLI & 5 NIR \& 4 RED & $30 \mathrm{~m}$ \\
\hline
\end{tabular}




\section{Knowledge of indigenous communities related to the benefits of mangrove forests}

Our study revealed the majority of local communities in SGK have deeply understood the benefits of mangrove forests for their life (Table 2). It related to their own experience when affected by many negative impacts of mangroves loss. More than $90 \%$ of the respondents from three different local indigenous communities, namely Rote, Sabu, and Timor showed high level of knowledge about the importance of mangrove ecosystems. They realized the existence of mangrove ecosystems had important roles to maintain the balance of environmental in the coastal area such as preventing abrasion, averting sea-water intrusion, and serving as windbreak. They were also aware that the mangrove forests are the sources of high economic products to fulfill their needs because these are the habitat for a number of sea organisms especially fish, crab, and shrimp. From their life experience, they sensed that the activity of illegal logging and sand mining really damaged the mangrove ecosystems and directly impacted the continuity of their life.

\section{Role of indigenous communities in mangrove rehabilitation in SGK}

A volunteer movement for mangroves rehabilitation in SGK was initiated by Juliman Messak family in 1994. This was encouraged by the negative impacts of mangrove loss for their family who lived in SGK. They had seven people in their family who provided a meaningful contribution to begin a reforestation program in mangroves, consisting of Mr. Messak, Mrs. Messak, and their five children. In the beginning, the most difficult challenge for doing this effort is no availability of plant materials for planting (i.e. seed and seedlings) caused by the majority of old mangroves had been cleared. Messak family should sail far to obtain the plant materials from mangrove forests in Oeteta and Pariti. It required around two hours of sailing from their home to the seed collection area. This activity was conducted in every Friday and Saturday for five years.
When the seeds had been collected, the Messak family planted them when the seawater had receded. However, their effort did not show a satisfying result. Besides having a lack of knowledge related to the silvicultural methods in mangroves, the openness condition of mangroves became an additional problem as the seeds were washed away by large sea waves. This problem is not only occurred in SGK, but also in other regions in the world. In Bangladesh, approximately $30-40 \%$ of planted propagules in mangrove reforestation were washed due to sea waves (Saenger and Siddiqi 1993). Another study from Vietnam also reported a similar trend where approximately $20-30 \%$ of mangrove seeds have lost from the reforestation zone due to the sea tide (Nguyen et al. 2016). Moreover, there was some community's livestock such as goats and cows that ate the mangrove seeds after the planting. Unfortunately, most local people still did not care about their effort, even though there were many constraints to recover the mangrove ecosystems in SGK. It needed almost two years for the other member of local indigenous communities to participate in the effort of mangrove rehabilitation together with Messak family. Before 2004, the practice of mangrove reforestation used direct planting with propagule that collected from other areas by communities. Their volunteer activity presented the prospective results where the mangrove cover significantly increase in 2004 (Figure 2). After a similar period, in 2004, the district government started to appreciate their effort and provided financial support. Furthermore, the support of mangrove experts from local universities (Politeknik Negeri Kupang) was helpful to improve the technical knowledge of communities for conducting mangrove reforestation. Starting from 2004, the local indigenous communities initiated to build traditional nursery to sow propagule to become seedling, thus it can be more effective to accelerate the activity of mangrove reforestation in SGK (Figure 4). As evidence, during 2004-2019, the land cover of mangrove forests expanded rapidly by approximately 264.69 ha and covered three villages area namely Oebelo, Tanah Merah, and Noelbaki (Figures 2 and 3).

Table 2. Response of local indigenous people relate to their knowledge about the benefit of mangrove forests in southeastern Gulf of Kupang (SGK), Indonesia

\begin{tabular}{|c|c|c|c|}
\hline Indicator & Aspect & $\begin{array}{l}\text { Yes } \\
(\%)\end{array}$ & $\begin{array}{l}\text { No } \\
(\%)\end{array}$ \\
\hline 1 & Mangrove forest is a breeding place of young fishers (a place for spawning). & 93.75 & 6.25 \\
\hline 2 & Mangrove forest is a place where shrimp live and grow. & 100 & 0 \\
\hline 3 & Mangrove forest is a place to live and develop crabs. & 100 & 0 \\
\hline 4 & Mangrove forests are a place where clams live and grow. & 100 & 0 \\
\hline 5 & Mangrove forest is a place to live and grow squid. & 96.88 & 3.13 \\
\hline 6 & Mangrove forests have a function and benefit in protecting the coast from abrasion. & 96.88 & 3.13 \\
\hline 7 & Mangrove forests have a function and benefit in protecting the coast of Panatai from tsunami & 96.88 & 3.13 \\
\hline 8 & Mangrove forests have a function and benefit in preventing water intrusion & 96.88 & 3.13 \\
\hline 9 & $\begin{array}{l}\text { Mangrove forests have a function and benefit in protecting human settlements from exposure to storms } \\
\text { and wind from the sea }\end{array}$ & 100 & 0 \\
\hline 10 & $\begin{array}{l}\text { Mangrove forests have a function and benefit in capturing mud / sediment / forming new / arising land } \\
\text { Average }\end{array}$ & $\begin{array}{l}93.75 \\
97.50\end{array}$ & $\begin{array}{l}6.25 \\
2.50\end{array}$ \\
\hline
\end{tabular}



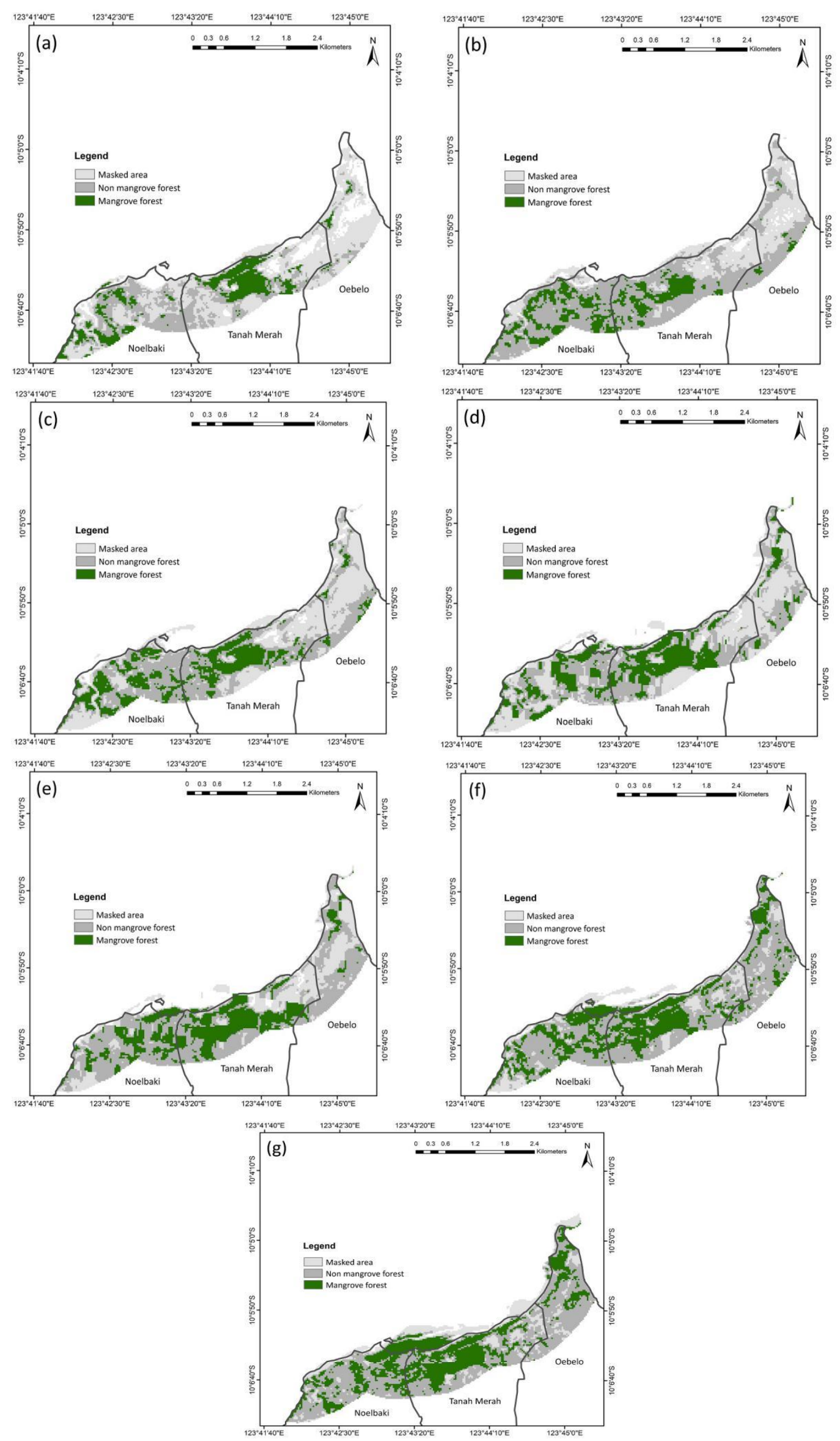

Figure 2. Mangroves cover in the study site from 1990 to 2019 derived from remote sensing data using LANDSAT images 


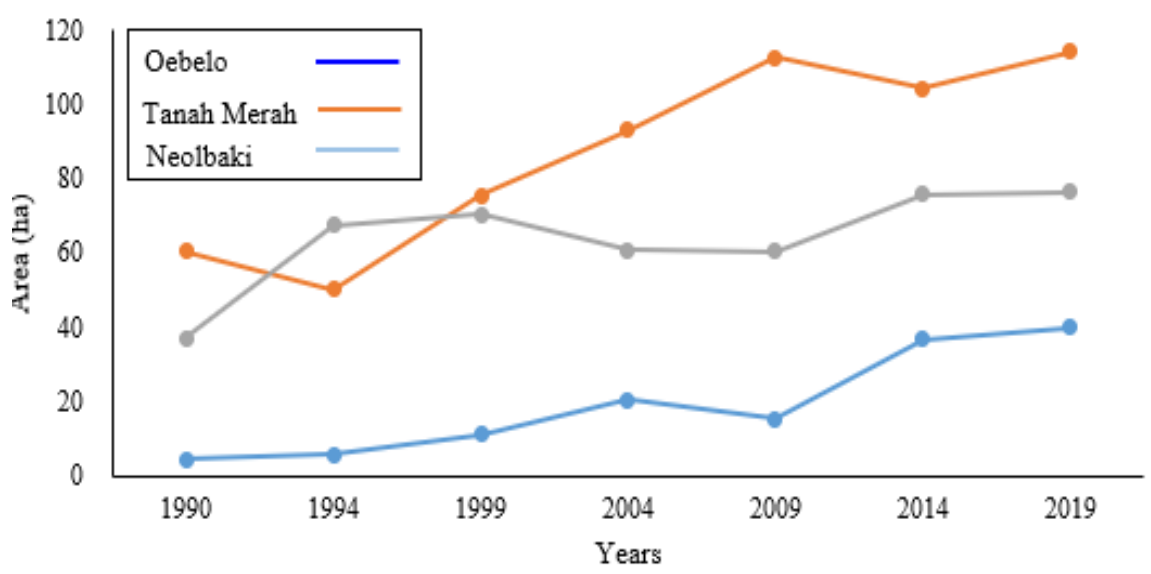

Figure 3. Trend of mangrove forest dynamics in southeastern Gulf of Kupang (SGK), Indonesia from 1990 to 2019 derived from multitemporal remote sensing data using LANDSAT images

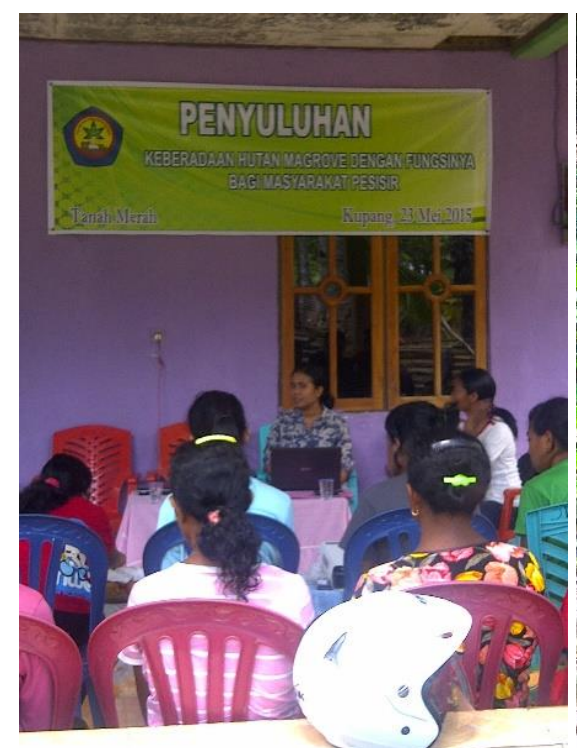

A

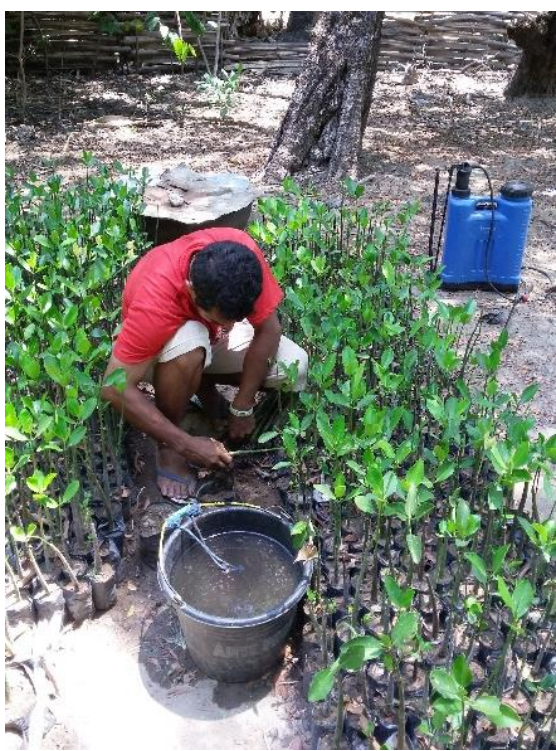

$\mathbf{B}$

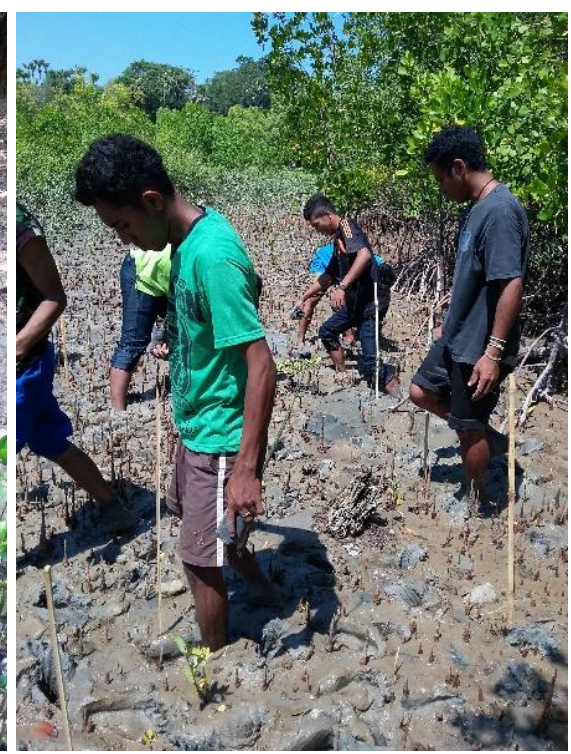

C

Figure 4. Documentation the activities of local indigenous communities for mangrove reforestation in southeastern Gulf of Kupang (SGK), Indonesia comprising of (A) silvicultural practices in mangrove; (B) sowing propagules to seedlings; (C) field planting with mangrove seedlings

\section{Local indigenous strategy to retain the existence of mangrove in SGK}

Reviewed from the long history of mangroves rehabilitation in SGK, a set of agreement was made by local indigenous communities living in the coastal areas of SGK. It consisted of several indigenous rules that bind the member of local communities and outsiders. Every indigenous people who conducting illegal logging in the mangroves would be expelled from the village, while a large fine (in the form of a cattle and money cash around two millions rupiah for each logged tree) was applied for outsiders who did the similar action. The member of indigenous communities was permitted to extract the deadwood from mangrove forests using special permits given by the Tumukung (Head of Village). The local societies were also given the opportunity to catch fish, crabs, snails, and shrimps as long as they did not damage the existence of mangroves. To minimize the risk of pollution in the mangroves area, every fisherman should conduct the maintenance of boat outside the mangroves, including cleaning the boat from oysters and filling the engine with oil and gasoline. Then, a specific area was prepared as parking lot for the boat when not be used. These policies have been implemented since 1999 and could sustain the presence of mangrove ecosystems in SGK until now. However, it will be impossible to adopt those rules in other places, particularly related to expel people from village. For explanation, the behavior of local 
societies in other places may highly different from SGK, thus it is required another policy for the same case such as imprisoning people to jail when they conduct illegal logging in mangroves. In addition, giving social services regarding reforestation activities in mangroves can become an option to provide a punishment for actor who disturbs mangrove ecosystems.

\section{Important learning from sustainable mangroves management in SGK}

The success story of sustainable mangrove management in SGK from reforestation to conservation efforts revealed the important role of local indigenous communities in natural resource management. In this case, the existence of societies was a center actor to retain the existence of mangrove forest after long-term effort of reforestation activities. It is in line with the results of several studies that community participation was a primary key to guarantee the continuity of reforestation in forest ecosystems (Ilman et al. 2016, Kusmana and Sukristijiono 2016, Matsvange et al. 2016). Our study showed that mangroves rehabilitation in SGK occurred through bottom-up scenario wherein at the early periods, it was initiated by the member of local indigenous community. Several studies reported that the use of bottom-up scheme was commonly more helpful than top-down, particularly for natural resource management.

This study also observed a high commitment from local indigenous community to sustain mangrove forests in SGK. It was evidenced by a set of indigenous rules that prevailed for every people who interacted with the mangroves area. A great attention of societies to a specific object was generally affected by certain factors, one of them is economic aspect (Aheto et al. 2016). From our study, it was obviously informed the most of indigenous community in SGK worked as fisherman who highly depends on fisheries products. After the degradation of mangroves occurred, the productivity of fisheries declined sharply and to fulfill their daily needs, the majority of community should sail far for catching fish. It indicated that there was a great motivation for community to recover mangroves, thus the number population of fish could increase again. This reality presented the importance of environmental sustainability for supporting human life. Referring to the bad experience in the previous time, the local indigenous communities provided the best efforts for mangrove reforestation. They believe that the recovery of mangrove forests can revive their previous life. Therefore, after the mangrove forest has build again, they determined a strict rule to retain the existence of mangrove. Interestingly, these rules were not only applicable to indigenous people, but also outside people who disturbed mangrove forests.

In conclusion, this study concluded that a series of situations became the fundamental of success in retaining the existence of mangrove ecosystems in SGK. First, the negative impacts of mangrove degradation affected the communities badly in relation to their livelihoods in fisheries and marine sector as well as other environmental impacts. Then, this situation led to the emergent of a local champion to initiate mangrove rehabilitation efforts which firstly did not get attention by most of the communities.
After some initial success, the efforts of the local champion was then followed by other members of communities, triggering a bigger scale of mangrove rehabilitation. Having the mangrove recovered, the communities set of highly strict local indigenous rules in which every indigenous people who conducting illegal

logging in the mangroves would be expelled from the village, while a large fine was given for outside people who did the similar action. The results of the success of mangrove rehabilitation in SGK was confirmed by the increasing extent of mangrove vegetation using remote sensing data. The case study of rehabilitation and conservation in SGK provided valuable learning for communities in other areas.

\section{ACKNOWLEDGEMENTS}

Thank you to Faculty of Forestry, Gadjah Mada University, Yogyakarta, Indonesia which provided financial support for this research. We also express our gratitude for the East Nusa Tenggara, Indonesia government who has given us permission to conduct research in Kupang.

\section{REFERENCES}

Aheto DW, Kankam S, Okyere I, Mensah E, Osman A, Jonah FE, Mensah JC. 2016. Community-based mangrove forest management: Implications for local livelihoods and coastal resource conservation along the Volta estuary catchment area of Ghana. Ocean Coast Manage 127: 43-54. DOI: 10.1016/j.ocecoaman.2016.04.006

Bengtsson M. 2016. How to plan and perform a qualitative study using content analysis. NursingPlus Open 2: 8-14. DOI: 10.1016/j.npls.2016.01.001

Budiharta S, Meijaard E, Wells JA, Abram NK, Wilson KA. 2016. Enhancing feasibility: Incorporating a socio-ecological systems framework into restoration planning. Environ Sci Policy 64: 83-92.

Eddiwan K. 2018. Success level of mangrove tree planting real in Kepulauan Meranti district, Riau, Indonesia. J Aquac Marine Biol 7: 213-218. DOI: 10.15406/jamb.2018.07.00211

Guannel G, Arkema K, Ruggiero P, Verutes G. 2016. The power of three: Coral reefs, seagrasses and mangroves protect coastal regions and increase their resilience. PLoS ONE. 11: 1-22. DOI: 10.1371/journal.pone.0158094

Ilman M, Dargusch P, Dart P, Onrizal. 2016. A historical analysis of the drivers of loss and degradation of Indonesia's mangroves. Land Use Policy. 54: 448-459. DOI: 10.1016/j.landusepol.2016.03.010

Islam MM, Borgqvist H, Kumar L. 2018. Monitoring mangrove forest landcover changes in the coastline of Bangladesh from 1976 to 2015. Geocarto Int 34: 1408-1426. DOI: 10.1080/10106049.2018.1489423

Kusmana C, Sukristijiono S. 2016. Mangrove resource uses by local community in Indonesia. J Nat Resour Environ Manag 6: 217-224. DOI: 10.19081/jpsl.2016.6.2.217

Le HD, Smith C, Herbohn J, Harrison S. 2012. More than just trees: Assessing reforestation success in tropical developing countries. J Rural Studies 28: 5-19. DOI: 10.1016/j.jrurstud.2011.07.006

Matatula J, Poedjirahajoe E, Pudyatmoko S, Sadono R. 2019. Spatial distribution of salinity, mud thickness and slope along mangrove ecosystem of the coast of Kupang District, East Nusa Tenggara, $\begin{array}{llll}\text { Indonesia. } & \text { Biodiversitas } 20: & 1624-1632 . & \text { DOI: }\end{array}$ 10.13057/biodiv/d200619

Matsvange D, Sagonda R, Kaundikiza M. 2016. The role of communities in sustainable land and forest management: The case of Nyanga, Zvimba and Guruve districts of Zimbabwe. Jàmbá: J Disaster Risk Studies 8: 1-11. DOI: 10.4102/jamba.v8i3.281 
Nguyen TP, Van Tam N, Quoi LP, Parnell KE. 2016. Community perspectives on an internationally funded mangrove restoration project: Kien Giang province, Vietnam. Ocean Coast Manage 119: 146-154. DOI: 10.1016/j.ocecoaman.2015.10.008

Richards DR, Friess DA. 2016. Rates and drivers of mangrove deforestation in Southeast Asia, 2000-2012. Proceedings of the National Academy of Sciences of the United States of America 113 344-349. DOI: 10.1073/pnas.1510272113

Saenger P, Siddiqi NA. 1993. Land from the sea: The mangrove afforestation program of Bangladesh. Ocean Coast Manag 20: 23-39. DOI: 10.1016/0964-5691(93)90011-M

Sihombing VS, Gunawan H, Sawitri R. 2017. Diversity and community structure of fish, plankton and benthos in Karangsong mangrove conservation areas, Indramayu, West Java, Indonesia. Biodiversitas 18: 601-608. DOI: 10.13057/biodiv/d180222
Susilo H, Takahashi Y, Yabe M. 2017. The opportunity cost of labor for valuing mangrove restoration in Mahakam Delta, Indonesia. Sustainability 9: 1-13. DOI: 10.3390/su9122169

Taillardat P, Friess DA, Lupascu M. 2018. Mangrove blue carbon strategies for climate change mitigation are most effective at the national scale. Biol Lett 14: 1-7. DOI: 10.1098/rsbl.2018.0251

Umroh, Adi W, Sari SP. 2016. Detection of Mangrove Distribution in Pongok Island. Procedia Environ Sci 33: 253-257. DOI: 10.1016/j.proenv.2016.03.076

Wylie L, Sutton-Grier AE, Moore A. 2016. Keys to successful blue carbon projects: Lessons learned from global case studies. Mar Pol 65: 76-84. DOI: 10.1016/j.marpol.2015.12.020

Zhang K, Ross M, Gann D. 2016. Remote sensing of seasonal changes and disturbances in mangrove forest: a case study from South Florida. Ecosphere 7: 1-23. 